\title{
A OBRIGATORIEDADE, GRATUIDADE E FINANCIAMENTO DA EDUCAÇÃO COMO UM DIREITO SOCIAL NO BRASIL
}

\author{
LA OBLIGATORIA, GRATUITA Y FINANCIAMIENTO DE LA EDUCACIÓN COMO \\ UN DERECHO SOCIAL EN BRASIL
}
THE OBLIGATORY, GRATUITY AND FINANCING OF EDUCATION AS A SOCIAL LAW IN BRAZIL

\author{
Kellcia Rezende SOUZA ${ }^{1}$ \\ Rosalina Dantas da SILVA ${ }^{2}$ \\ Ana Paula Moreira de SOUSA ${ }^{3}$
}

RESUMO: O estudo teve o intuito de analisar a regulamentação do direito à educação no Brasil a partir da obrigatoriedade, gratuidade e financiamento. Para tanto, com o referencial da abordagem qualitativa, foi realizada uma pesquisa bibliográfica e documental, cuja fonte foi a Constituição Federal de 1988 e as suas respectivas emendas. Foi possível evidenciar que o país avançou na proteção jurídica da ampliação dos anos de escolaridade obrigatória e gratuita, mas, nos últimos anos, com o financiamento educacional sendo um dos alvos da Emenda Constitucional n. 95/2016, o congelamento de investimento de recursos públicos ameaça a cobertura, a expansão e, consequentemente, a garantia do direito à educação.

PALAVRAS-CHAVE: Direito à educação. Financiamento. Gratuidade. Obrigatoriedade.

RESUMEN: El estudio tuvo el propósito de analizar la reglamentación del derecho a la educación en Brasil a partir de la obligatoriedad, gratuidad y financiamiento. Para ello, con el referencial del abordaje cualitativo, se realizó una investigación bibliográfica y documental, cuya fuente fue la Constitución Federal de 1988 y sus respectivas enmiendas. Es posible evidenciar que el país avanzó en la protección jurídica de la ampliación de los años de escolaridad obligatoria y gratuita, pero en los últimos años, con el financiamiento educacional siendo uno de los objetivos de la Enmienda Constitucional n. 95/2016, la congelación de la inversión de recursos públicos amenaza la cobertura, la expansión y, por consiguiente, la garantía del derecho a la educación.

PALABRAS CLAVE: Derecho a la educación. Financiación. Gratuidad. Obligatorio.

ABSTRACT: The purpose of this study was to analyze the regulation of the right to education in Brazil based on compulsory, gratuitous and financing. For that, with the reference of the

\footnotetext{
${ }^{1}$ Universidade Federal da Grande Dourados (UFGD), Dourados - MS - Brasil. Professora Faculdade de Educação. ORCID: <https://orcid.org/0000-0002-8663-4615>. E-mail: kellcia@hotmail.com

${ }^{2}$ Universidade Federal da Grande Dourados (UFGD), Dourados - MS - Brasil. Técnica-administrativa revisora textual. ORCID: <https://orcid.org/0000-0002-2866-6854>. E-mail: RosalinaSilva@ufgd.edu.br

${ }^{3}$ Faculdades Magsul, Ponta Porã - MS - Brasil. Professora do curso de Pedagogia e Educação Física. ORCID: <https://orcid.org/0000-0003-0496-4408>. E-mail: profap.educa@gmail.com
} 
qualitative approach, a bibliographical and documentary research was carried out, whose source was the Federal Constitution of 1988 and its respective amendments. It was possible to show that the country has advanced in the legal protection of the expansion of years of compulsory and free schooling, but in recent years, with educational funding being one of the targets of Constitutional Amendment n. 95/2016, the freezing of investment of public resources threatens to cover, expand and, consequently, guarantee the right to education.

KEYWORDS: Right to education. Financing. Gratuity. Obligatory.

\section{Introdução}

Considerando que a educação como direito se inscreve no campo das políticas públicas e a existência de um direito implica a existência de um sistema normativo (BOBBIO, 1992), o presente estudo tem como objetivo analisar o direito à educação no Brasil a partir da obrigatoriedade, gratuidade e financiamento educacional. A fim de propiciar o alcance do objetivo estabelecido, foi realizada uma pesquisa bibliográfica e documental com enfoque qualitativo. A fonte documental contempla a Constituição Federal de 1988 e as suas respectivas emendas, tendo como categorias de análise a previsão da obrigação, a oferta gratuita do ensino e a despesa pública destinada à educação.

No Brasil, segundo Flach (2009), houve um avanço histórico na definição e regulamentação do direito à educação, que tem a Constituição Federal de 1988 como seu principal marco. Porém, não podemos perder de vista que o Estado deve garantir o direito educacional visando sempre a expansão da sua oferta de forma gratuita e o provimento dos meios concretos necessários para a sua efetivação, no qual o financiamento é crucial.

Sabemos que compreender o direito à educação em um país no tocante ao seu ordenamento normativo compreenderia uma investigação mais abrangente que considerasse os elementos atinentes: às perspectivas de gestão, à educação inclusiva, às condições estruturais e materiais, ao currículo, à formação e valorização dos profissionais da educação e à avaliação. Contudo, abarcar todos esses aspectos esbarraria na necessidade da delimitação necessária para a garantia da execução da presente pesquisa. Frente a esse cenário, optamos pela análise da obrigatoriedade, gratuidade e financiamento educacional.

\section{Obrigatoriedade e gratuidade do direito à educação no Brasil}

O direito à educação propiciou, historicamente, a função de ser a ponte entre os direitos políticos e os direitos sociais. Desse modo, garantir um nível mínimo de escolarização ao 
indivíduo torna-se um direito/dever intimamente relacionado ao exercício da cidadania. De acordo com Flach (2009), além da obrigatoriedade, a gratuidade é outro princípio imperativo na garantia desse direito e para preservar seu caráter igualitário. O Estado não pode tornar o ensino obrigatório sem torná-lo gratuito, pois a obrigatoriedade e gratuidade da educação básica estão associadas ao compromisso com o desenvolvimento pessoal, social e político do ser humano. É pensar no desenvolvimento da nação de um país.

Conforme a autora, a educação deve estar assegurada em um amplo marco jurídico, de modo que potencialize não só sua garantia legal mas, principalmente, sua garantia material, pois o usufruto desse direito representa a criação de condições individuais e coletivas para o desenvolvimento da consciência sobre a realidade em que se vive e sobre as relações existentes nos contextos dos quais os sujeitos são históricos, sociais, culturais, econômicos e políticos. Trata-se, pois, do direito que possibilita os instrumentos concretos para lograr a cidadania de maneira efetiva.

Ao garantir o direito à educação básica obrigatória e gratuita, o Estado passa a assegurar uma condição universal para o próprio usufruto dos direitos civis. Assim, Cury (2002) aponta que a relevância da educação primária tornada como um direito imprescindível do cidadão e um dever do Estado impuseram a obrigatoriedade e gratuidade como modos de torná-lo acessível a todos, indistintamente.

$\mathrm{Na}$ educação formal, universalização, obrigatoriedade e gratuidade formam parte de um único processo. A obrigatoriedade e a gratuidade da educação representam, simultaneamente, a garantia da universalidade do acesso à educação, ao tempo em que asseguram o direito do homem à educação. A universalização do ensino representa, assim, o mecanismo mediante o qual é possível garantir a igualdade de acesso à escola (DIAS, 2007, p. 450).

"Por isso, o direito à educação escolar primária inscreve-se dentro de uma perspectiva mais ampla dos direitos civis dos cidadãos". A garantia da educação básica enquanto direito decorreu de um processo histórico de lutas conduzidas por uma concepção democrática da sociedade em que se almeja a igualdade de oportunidades ou mesmo a igualdade de condições sociais e buscar essa premissa significa postular a ampliação da obrigatoriedade e gratuidade enquanto princípios que expandem a proteção do direito (CURY, 2002, p. 248).

Frente ao exposto, vejamos como os princípios de obrigatoriedade e gratuidade são tratados na constituição brasileira. No Brasil, a Constituição Federal de 1988 endossou, em seu artigo n. 6, a educação como um direito social. Cury (2002) enfatiza que essa condição do constitucionalismo brasileiro colocou a educação enquanto um princípio da dignidade da pessoa humana como o valor maior do Estado, na medida em que, concomitantemente a outros direitos 
sociais, consagra-a como um direito fundamental. Para Oliveira e Araújo (2005, p. 6), a Constituição Federal brasileira foi um marco normativo para o país, à medida que "[...] assinalou uma perspectiva mais universalizante dos direitos sociais e avançou na tentativa de formalizar, do ponto de vista do sistema jurídico brasileiro, um Estado de bem-estar social numa dimensão inédita em sua história".

Sarlet (2005) aponta que os direitos fundamentais, especialmente a educação e a saúde, devem ser expressos constitucionalmente. Esses direitos exigem ampla proteção jurídica, uma vez que representam as condições vitais para garantir a dignidade humana. Especificamente sobre o direito à educação, foram incluídos nove artigos, nos quais se encontra explícita uma série de aspectos que envolvem a sua concretização. No artigo 205, consta que a educação é direito de todos e dever do Estado e da família.

O artigo 206 estabelece os princípios que fundamentam a oferta do ensino no país, quais sejam, "I - igualdade de condições para o acesso e permanência na escola; II - Liberdade de aprender, ensinar, pesquisar e divulgar o pensamento, a arte e o saber [...] IV - gratuidade do ensino público nos estabelecimentos oficiais". O artigo 208 apresenta nomeadamente o direito à Educação, que será efetivado mediante a garantia de:

I - educação básica obrigatória e gratuita dos 4 (quatro) aos 17 (dezessete) anos, assegurado inclusive para os que a ele não tiveram acesso na idade própria

II - progressiva universalização do ensino médio gratuito ${ }^{5}$;

III - atendimento educacional especializado aos portadores de deficiência, preferencialmente na rede regular de ensino;

IV - educação infantil, em creche e pré-escola, às crianças até 5 (cinco) anos de idade ${ }^{6}$;

$\mathrm{V}$ - acesso aos níveis mais elevados do ensino, da pesquisa e da criação artística, segundo a capacidade de cada um;

VI - oferta de ensino noturno regular, adequada às condições do educando;

VII - atendimento ao educando, em todas as etapas da educação básica, por meio de programas suplementares de material didático escolar, transporte, alimentação e assistência à saúde ${ }^{7}$ (BRASIL, 1988).

Os parágrafos $1^{\circ}, 2^{\circ}$ e $3^{\circ}$ do artigo 208 definem, ainda, que o acesso ao ensino obrigatório e gratuito é direito público subjetivo; o não-oferecimento do ensino obrigatório pelo Poder Público, ou sua oferta irregular, importa responsabilidade da autoridade competente. A educação, na Constituição Federal de 1988, foi concebida como obrigatória e gratuita e, quando ofertada pelos poderes públicos, tornou-se um direito público subjetivo, pelo qual o indivíduo

\footnotetext{
${ }^{4}$ Redação dada pela Emenda Constitucional n ${ }^{\circ} 59$ de 2009.

${ }^{5}$ Redação dada pela Emenda Constitucional n ${ }^{\circ} 14$ de 1996.

${ }^{6}$ Redação dada pela Emenda Constitucional n ${ }^{\circ} 53$ de 2006.

${ }^{7}$ Redação dada pela Emenda Constitucional n ${ }^{\circ} 59$ de 2009.
} 
possui uma esfera de ação inviolável, na qual o poder público não pode penetrar (DUARTE, 2004).

[...] o direito público subjetivo confere ao indivíduo a possibilidade de transformar a norma geral e abstrata contida num determinado ordenamento jurídico em algo que possua como próprio. A maneira de fazê-lo é acionando as normas jurídicas (direito objetivo) e transformando-as em seu direito (direito subjetivo). $\mathrm{O}$ interessante é notar que o direito público subjetivo configura-se como um instrumento jurídico de controle da atuação do poder estatal, pois permite ao seu titular constranger judicialmente o Estado a executar o que deve (DUARTE, 2004, p. 113).

O direito público subjetivo é uma norma jurídica constitucional que assegura a todo cidadão, investido legitimamente de seu direito, o poder para exigir o cumprimento da legislação e, ao Estado, a obrigação de promovê-lo. No caso da educação, significa que o titular deste direito é qualquer pessoa, de qualquer idade, que não tenha tido acesso à escolaridade obrigatória na idade apropriada ou não. Ele é subjetivo porque é inerente ao seu titular e como o sujeito deste dever é o Estado, constitui-se num direito público. No entender de Duarte (2004), é instrumento jurídico de controle da ação estatal, pois possibilita ao cidadão investido de seu direito exigir judicialmente do Estado o cumprimento de seus deveres.

A obrigatoriedade e a gratuidade da educação no Brasil sofreram diversas alterações por meio de revisões no texto constitucional ao longo dos últimos vinte anos, dentre elas, a ampliação da escolarização obrigatória. Enquanto o texto original previa educação obrigatória e gratuita destinada ao Ensino Fundamental, que compreendia crianças entre 7 e 14 anos, a Emenda Constitucional n. 59/2009 estabeleceu a idade de 4 a 17 anos, o que totaliza 14 anos de tempo escolar obrigatório.

Segundo Flach (2009), a ampliação dos anos de escolaridade foi um avanço para a realidade educacional brasileira, o que demonstra que a referida Emenda Constitucional consiste em um marco para a educação do país. A expansão do tempo de escolaridade obrigatória e gratuita de quatro a 17 anos implica na garantia legal de um maior número de crianças e adolescentes na escola. Entendemos que se trata de uma conquista histórica forjada tanto no contexto do desenvolvimento econômico, sociocultural e, principalmente, quanto na luta social pela ampliação da expansão do direito à educação inalienável a todos.

O contexto educacional brasileiro, sobretudo nas duas últimas décadas, apresentou à educação básica uma configuração de profundas mudanças referentes às políticas educacionais, entre as quais, a ampliação dos anos de escolaridade obrigatória no país se constituiu enquanto uma das pautas centrais. Essas mudanças decorreram, principalmente, da necessidade de 
superação do cenário da educação brasileira, marcado, historicamente, pelo fracasso e pela exclusão social (SENNA, 2008).

\section{A regulamentação do financiamento educacional}

O financiamento é o principal indicador do esforço de cada governo nacional para expandir a cobertura da oferta, garantir a permanência e a qualidade educacional. A ampliação de investimentos públicos para a educação, em valores reais, tende a potencializar o desenvolvimento econômico e, principalmente, social de uma nação. Por outro lado, a manutenção ou redução pode desencadear uma mudança de prioridades por parte do país, que trará impactos à efetiva concretização do direito à educação (TROJAN, 2010).

A concretização da educação como um bem social, obrigatório e gratuito, garantido constitucionalmente, demandará custeio. Assim, o aporte necessário para a manutenção das instituições de ensino, remuneração e valorização dos profissionais da educação e construção de novas estruturas físicas, ou seja, para subsidiar as políticas educacionais, advêm da própria sociedade, mediante o pagamento de impostos que serão redistribuídos pelo Estado. Os investimentos educacionais devem estar previstos no orçamento ${ }^{8}$ a partir das receitas de um país e devem ser classificados de acordo com as normatizações. Porém, o percentual de transferência para a área demandará a normatização de um aparato legal (OLIVEIRA; MORAES; DOURADO, 2009).

O Brasil institui, em sua constituinte, a regulamentação do financiamento educacional. A Carta Magna brasileira, no que concerne à organização e divisão de responsabilidades no provimento financeiro da educação entre os entes federados, estabelece, no artigo 211, que a União, os estados, o Distrito Federal e os municípios organizarão seus sistemas de ensino em regime de colaboração. Esse artigo também define que os municípios atuarão no Ensino fundamental e na Educação Infantil; Estados e o Distrito Federal serão responsáveis,

8 "O orçamento é uma fase do planejamento, ou seja, ele é uma lei que orienta a execução dos planos governamentais. Na Lei Orçamentária, devem estar previstas todas as receitas e todas as despesas públicas correspondentes a um ano. Assim, no orçamento, seja da união, do estado, do Distrito Federal ou do município, devem estar previstas todas as fontes de receitas destinadas, por exemplo, à educação (impostos, transferências, salário-educação e outras) e todas as despesas que serão realizadas, compreendendo os gastos com pessoal, material, serviços, obras, equipamentos e outros. Receita é o conjunto dos rendimentos de um estado, de uma entidade ou de uma pessoa, destinados a enfrentar os gastos necessários. A receita pública é composta por receitas correntes e receitas de capital. A receita de impostos consiste na soma de tributos que o Estado exige de pessoas físicas e jurídicas, coercitivamente, sem lhes oferecer uma contraprestação direta e determinada" (OLIVEIRA; MORAES; DOURADO, 2009, p. 2-3). 
prioritariamente, pelo Ensino Fundamental e Médio; e a União organizará o sistema federal de ensino e dos territórios (BRASIL, 1988).

A organização do financiamento no sistema educacional do Brasil, conforme a Constituição Federal é caracterizada pela divisão de competências e responsabilidades entre União, estados, Distrito Federal e municípios dos diferentes níveis, etapas e modalidades educacionais. Essa determinação, que define prioridades do ensino, não veda ou restringe a atuação dos entes federados em outros níveis e etapas da educação brasileira, mas é considerada como um parâmetro para a gestão dos recursos orçamentários (SOUZA, 2017).

A estrutura legal do financiamento do país é baseada nas competências atribuídas aos seus entes federados: União, Estados, Distrito Federal e Municípios. Cabe à União aplicar seu orçamento na rede federal de ensino e, também, na transferência de recursos para compor as receitas dos Estados e Municípios. Nesse viés, a normatização do financiamento no país é pautada pelo regime de colaboração (ABRAHÃO, 2005).

O artigo 212 destaca que a União aplicará, anualmente, nunca menos de 18\%, e os Estados, o Distrito Federal e os Municípios, 25\%, no mínimo, da receita resultante de impostos, compreendida aquela proveniente de transferências, na manutenção e desenvolvimento do ensino. Sena (2008) destaca que é importante fazer a ressalva de que as constituintes estaduais e as leis orgânicas dos municípios poderão estabelecer percentuais maiores de aplicação dos recursos para a educação.

Os recursos para o financiamento educacional no Brasil são oriundos das arrecadações de impostos da sociedade, o que representa que a parcela expressiva das fontes da União, estados, Distrito Federal e Municípios é proveniente do recolhimento tributário. Abrahão (2005) considera que, ao vincular legalmente um percentual para os gastos com a educação mediante o fluxo de receitas, o país assegura uma importante ferramenta jurídica para garantir a concreta disponibilidade de recursos para o cumprimento da responsabilidade do poder público na garantia do direito à educação.

Cada governante, quando chega ao poder, não pode usar o dinheiro público como bem entender. Para garantir a educação de todas e todos, a Constituição Federal estabelece um mínimo de gastos anuais que União, estados, Distrito Federal e municípios devem destinar às políticas de educação. São as chamadas despesas obrigatórias com o ensino. (RIZZI, GONZALEZ; XIMENES, 2011, p. 43)

O inciso $3^{\circ}$ institui que a distribuição dos recursos públicos assegurará a prioridade do atendimento às necessidades do ensino obrigatório, no que se refere à universalização, garantia 
de padrão de qualidade e equidade, nos termos do plano nacional de educação (BRASIL, 1988). Os demais incisos do referido artigo destacam:

$\S 1^{\circ}$ A parcela da arrecadação de impostos transferida pela União aos Estados, ao Distrito Federal e aos Municípios, ou pelos Estados aos respectivos Municípios, não é considerada, para efeito do cálculo previsto neste artigo, receita do governo que a transferir.

$\S 2^{\circ}$ Para efeito do cumprimento do disposto no "caput" deste artigo, serão considerados os sistemas de ensino federal, estadual e municipal e os recursos aplicados na forma do art. 213.

$\S 3^{\circ}$ A distribuição dos recursos públicos assegurará prioridade ao atendimento das necessidades do ensino obrigatório, no que se refere a universalização, garantia de padrão de qualidade e equidade, nos termos do plano nacional de educação.

$\S 4^{\circ}$ Os programas suplementares de alimentação e assistência à saúde previstos no art. 208, VII, serão financiados com recursos provenientes de contribuições sociais e outros recursos orçamentários.

$\S 5^{\circ}$ A educação básica pública terá como fonte adicional de financiamento a contribuição social do salário-educação, recolhida pelas empresas na forma da lei.

$\S 6^{\circ}$ As cotas estaduais e municipais da arrecadação da contribuição social do salário-educação serão distribuídas proporcionalmente ao número de alunos matriculados na educação básica nas respectivas redes públicas de ensino (BRASIL, 1988).

É notório o fato de o texto constitucional salientar que os recursos deverão ser empenhados, prioritariamente, ao ensino obrigatório, vislumbrando a sua universalidade com equidade e qualidade. Além da vinculação de impostos, a Constituição brasileira prevê as seguintes fontes de financiamento da educação: contribuições (salário-educação, renda de loteria, contribuições sobre o lucro e seguridade social); desvinculação de receitas da União; e operações de crédito. Embora se observem diversificadas fontes, a vinculação de impostos ainda constitui a principal fonte de receitas no financiamento da educação obrigatória pública, tanto por parte da União quanto dos estados, Distrito Federal e municípios (GEMAQUE, 2011).

O artigo 213 expõe que os recursos públicos serão destinados às escolas públicas, podendo ser dirigidos a escolas comunitárias, confessionais ou filantrópicas, definidas em Lei. Além desses dois artigos, a constituinte apresenta, nos incisos do artigo 206, a valorização dos profissionais da educação, questão que está relacionada ao financiamento educacional.

V - valorização dos profissionais da educação escolar, garantidos, na forma da lei, planos de carreira, com ingresso exclusivamente por concurso público de provas e títulos, aos das redes públicas; VIII - piso salarial profissional nacional para os profissionais da educação escolar pública, nos termos de lei federal (BRASIL, 1988). 
A valorização dos profissionais da educação, assegurada na Carta Magna brasileira, decorreu da regulamentação da Emenda Constitucional n. 53/2006. Esse instrumento jurídico também institui a criação do Fundo de Manutenção e Desenvolvimento da Educação Básica e de Valorização dos Profissionais da Educação (FUNDEB), que é de natureza contábil e com previsão de duração de 14 anos. O objetivo do fundo consiste em garantir o financiamento do desenvolvimento e da manutenção da educação, bem como a melhoria da valorização dos profissionais envolvidos na educação por todos os entes federados. $\mathrm{O}$ artigo n. 60 do Ato das Disposições Constitucionais Transitórias ${ }^{9}$ da Constituição Federal também dispõe:

I - a distribuição dos recursos e de responsabilidades entre o Distrito Federal, os Estados e seus Municípios é assegurada mediante a criação, no âmbito de cada Estado e do Distrito Federal, de um Fundo de Manutenção e Desenvolvimento da Educação Básica e de Valorização dos Profissionais da Educação - FUNDEB, de natureza contábil;

II - os Fundos referidos no inciso I do caput deste artigo serão constituídos por $20 \%$ (vinte por cento) dos recursos a que se referem os incisos I, II e III do art. 155; o inciso II do caput do art. 157; os incisos II, III e IV do caput do art. 158; e as alíneas a e b do inciso I e o inciso II do caput do art. 159, todos da Constituição Federal, e distribuídos entre cada Estado e seus Municípios, proporcionalmente ao número de alunos das diversas etapas e modalidades da educação básica presencial, matriculados nas respectivas redes, nos respectivos âmbitos de atuação prioritária estabelecidos nos $\S \S 2^{\circ}$ e $3^{\circ}$ do art. 211 da Constituição Federal (BRASIL, 1988).

O FUNDEB determina, pois, a distribuição proporcional dos recursos aos Estados e Municípios conforme o número de alunos matriculados nas respectivas redes públicas de educação básica. Sena (2008) esclarece que, um dos avanços expressivos do FUNDEB, que substituiu o Fundo de Manutenção e Desenvolvimento do Ensino Fundamental e de Valorização do Magistério (FUNDEF), reside, principalmente, na sua abrangência, que contempla, como um mecanismo de financiamento, todas as etapas da educação básica, diferentemente do fundo anterior, que delimitava apenas o Ensino Fundamental enquanto única etapa para a destinação do fundo.

No entender de Castro e Carvalho (2013), a Constituição Federal Brasileira de 1988 e suas consequentes emendas não só ampliaram o gasto educacional, mas expandiram a estrutura institucional de competências e responsabilidade compartilhada pela educação obrigatória brasileira entre os entes federados. Todavia, é importante ressaltar que essa expansão não traduz necessariamente a exclusividade dos entes em financiar as ações educacionais. Mesmo com a

9 A Constituição Federal brasileira, do ponto de vista estrutural, contém um preâmbulo, o corpo e um Ato das Disposições Constitucionais Transitórias. A finalidade do ato visa estabelecer regras de transição entre um antigo e um novo ordenamento jurídico, amparado pela proteção constitucional (CANOTILHO, 2003). 
institucionalização do regime de colaboração, o financiamento educacional depende significativamente do aporte de recursos da união, sobretudo se consideramos as assimetrias de arrecadação entre os estados e municípios brasileiros.

Embora a Constituição Federal confira maior proteção jurídica ao orçamento educacional, é preciso registrar que, ao final do ano de 2016, o congresso do país aprovou a Emenda Constitucional n. 95/2016, que alterou o Ato das Disposições Transitórias para instituir o Novo Regime Fiscal. Essa normatização instituiu o Novo Regime Fiscal no âmbito dos Orçamentos públicos e da Seguridade Social da União, que passará a vigorar pelos próximos vinte exercícios financeiros (BRASIL, 2016). Especificamente sobre a educação, a emenda dispõe:

Art. 110. Na vigência do Novo Regime Fiscal, as aplicações mínimas em ações e serviços públicos de saúde e em manutenção e desenvolvimento do ensino equivalerão:

I - no exercício de 2017, às aplicações mínimas calculadas nos termos do inciso I do $\S 2^{\circ}$ do art. 198 e do caput do art. 212, da Constituição Federal;

II - nos exercícios posteriores, aos valores calculados para as aplicações mínimas do exercício imediatamente anterior, corrigidos na forma estabelecida pelo inciso II do $\S 1^{\circ}$ do art. 107 deste Ato das Disposições Constitucionais Transitórias".

"Art. 111. A partir do exercício financeiro de 2018, até o último exercício de vigência do Novo Regime Fiscal, a aprovação e a execução previstas nos $\S \S 9^{\circ}$ e 11 do art. 166 da Constituição Federal corresponderão ao montante de execução obrigatória para o exercício de 2017, corrigido na forma estabelecida pelo inciso II do $\S 1^{\circ}$ do art. 107 deste Ato das Disposições Constitucionais Transitórias" (BRASIL, 2016).

A referida Emenda Constitucional designa que os recursos destinados à educação pela União entre o período de 2018 a 2036 serão equivalentes aos $18 \%$ das receitas de impostos, tendo como referência os apurados em 2017, que só poderão ser alterados anualmente, de acordo com a inflação acumulada conforme o Índice Nacional de Preços ao Consumidor Amplo (IPCA). Isso significa que, independente do aumento das receitas de impostos do país, não serão ampliados os recursos para a educação.

Monlevade (2014, p. 66-67), em análise sobre o financiamento da educação no Brasil, esclareceu que a Constituição Federal de 1967 adotou a mesma lógica, ao conservar os percentuais de impostos para a educação dos Estados e Municípios e retirar o dever constitucional da União. O autor esclarece que essa legislação foi contraditória, pois “"[...] exatamente quando o governo federal arrecadou as maiores receitas da história, o aumento de 
encargos financeiros de todas as esferas administrativas foi viabilizado pelo corte na qualidade da educação pública e nos salários de seus profissionais".

A desvinculação de recursos financeiros representa um grave atentado para as políticas públicas de manutenção e desenvolvimento da educação e, em consequência, para a garantia do direito público subjetivo. Uma nação que priorize a educação jamais pode adotar a estagnação dos recursos enquanto meta para a área, sobretudo em um país que depende do aporte financeiro da União para compensar distorções da arrecadação proveniente das fontes fiscais assimétricas dos seus estados e municípios (MONLEVADE, 2014).

\section{Considerações finais}

O aparato legal deve ter como marco a Constituição Federal de um país, que é o principal instrumento jurídico para a construção da normatividade e, consequentemente, para a proteção do direito às atividades educativas. Nesse sentido, a Carta Magna brasileira reconhece a educação como um direito social e com características dos direitos da personalidade, quando a assegura como pública e subjetiva, dotada de proteção civil, porém, não deixando de ser um direito social.

Após três décadas da Constituição Federal vigente, observamos que a obrigatoriedade e gratuidade foram ampliadas nesse período, de modo que a proteção jurídica não ficasse restrita apenas a uma etapa da educação básica, o Ensino Fundamental. Assim, a Emenda Constitucional n. 59/2009 representa um marco político e normativo no tocante ao direito à educação no Brasil.

Nesse sentido, as reservas constitucionais do financiamento vinculadas à gratuidade, universalização do direito à educação básica e seu caráter obrigatório para as pessoas de 4 a 17 anos, para Souza (2017), não só contêm um horizonte equalizador, como também são viabilizadores das políticas educacionais no país.

Por outro lado, nos últimos anos, a Constituição Federal tem sofrido emendas que colocam em risco a garantia dos direitos sociais. No caso da educação, a Emenda Constitucional n. 95/2016, que alterou o Ato das Disposições Transitórias para instituir o Novo Regime Fiscal, representa uma grave medida que impede a ampliação de investimentos de recursos na área. Somado a isso, o FUNDEB, regulamentado pela Emenda Constitucional n. 53/2006, tem sua vigência assegurada só até 2020.

Esse fundo é a principal fonte de financiamento da educação básica e uma política pública educacional que tem assegurado a distribuição de recursos de forma equitativa, o que 
traz desdobramentos na consolidação do regime de colaboração entre os entes federados, municípios, estados e união.

Embora o Brasil tenha avançado do ponto de vista normativo na ampliação da obrigatoriedade e gratuidade, a materialização desse direito está seriamente comprometida se considerarmos os retrocessos impostos a garantia do financiamento público, que é determinante para vislumbrar a expansão da cobertura educacional do país nos diferentes níveis, etapas e modalidades educacionais.

\section{REFERÊNCIAS}

ABRAHÃO, J. Financiamento e gasto público da educação básica no Brasil e comparações com alguns países da OCDE e América Latina. In: Educação e Sociedade, Campinas, v. 26, n. 92, p. 841-858, 2005.

BRASIL. Constituição da República Federativa do Brasil de 1988. Constituição da República Federativa do Brasil. Brasília: Senado, 1988.

BRASIL. Emenda Constitucional n. 95, de 15 de dezembro de 2016. Altera o Ato das Disposições Constitucionais Transitórias, para instituir o Novo Regime Fiscal, e dá outras providências. Diário Oficial da República Federativa do Brasil, Brasília: 2016.

BOBBIO, N. A Era dos direitos. Rio de Janeiro: Campus, 1992.

CANOTILHO, J. J. G. Direito constitucional e teoria da Constituição. Coimbra: Almedina, 2003.

CASTRO, J. A.; CARVALHO, C. H. A de. Necessidades e possibilidades para o financiamento da educação brasileira no plano nacional de educação. In: Educação e Sociedade [online], v.34, n.124, p.829-849, 2013.

CURY, C. R. J. Direito à educação: direito à igualdade, direito à diferença. In: Cadernos de Pesquisa, São Paulo, n.116, p. 245-262. Jul. 2002.

DIAS, A. A. Da educação como direito humano aos direitos humanos como princípio educativo. In: SILVEIRA, R. M. G. et al. Educação em Direitos Humanos: Fundamentos teórico-metodológicos. João Pessoa: Editora Universitária, p. 441-456, 2007.

DUARTE, C. S. Direito público subjetivo e políticas educacionais. In: São Paulo em Perspectiva, São Paulo, v. 18, n. 2, p. 113-118, 2004.

FLACH, S. de F. O direito à educação e sua relação com a ampliação da escolaridade obrigatória no Brasil. Ensaio: Avaliação e Políticas Públicas em Educação, Rio de Janeiro, v. 17, n. 64, p. 495-520, 2009.

GEMAQUE, R. M. O. Políticas de financiamento e direito à educação básica: o Fundef e o Fundeb. In: SER Social, Brasília, v. 13, n. 29, p. 90-112, 2011. 
MONLEVADE, J. A. C. Recursos públicos para a educação: percentual irrevogável do PIB. In: Jornal de Políticas Educacionais, Curitiba, n. 16, p. 66 - 74, 2014.

OLIVEIRA, R. P.; ARAÚJO, G. C. Qualidade do ensino: uma nova dimensão da luta pelo direito à educação. In: Revista Brasileira de Educação, Rio de Janeiro, n. 28, p. 5-24, 2005.

OLIVEIRA, J. F.; MORAES, K. N. DOURADO, L. F. O financiamento da educação básica: limites e possibilidades. MEC: Escola de Gestores, 2009.

RIZZI, E.; GONZALEZ, M.; XIMENES, S. Direito Humano à Educação. $2^{a}$ ed. Curitiba: Plataforma Dhesca Brasil - Coleção Manual de Direitos Humanos, 2011.

SARLET, I. W. A Eficácia dos direitos fundamentais. 5 ed. Porto Alegre: Livraria do Advogado, 2005.

SENA, P. A legislação do FUNDEB. In: Cadernos de Pesquisa, São Paulo, v. 38, n. 134, p. 319-340, 2008.

SOUZA, K. R. Direito à educação nos países membros do Mercosul: um estudo comparado. 2017. 346f. Tese (Doutorado em Educação Escolar) - Universidade Estadual Paulista, Araraquara-SP, 2017.

TROJAN, R. M. Estudo comparado sobre políticas educacionais na América Latina e a influência dos organismos multilaterais. In: Revista Brasileira de Política e Administração da Educação, Brasília, v.26, n.1, p. 55-74, jan./abr. 2010.

\section{Como referenciar este artigo}

SOUZA, Kellcia Rezende; SILVA, Rosalina Dantas; SOUSA, Ana Paula Moreira. A obrigatoriedade, gratuidade e financiamento da educação como um direito social no Brasil. Revista on line de Política e Gestão Educacional, Araraquara, v. 23, n. 2, p. 328-340, maio/ago., 2019. E-ISSN:1519-9029. DOI: 10.22633/rpge.v23i2.12363

Data de Submissão: 17/01/2019

Revisões Requeridas: 18/02/2019

Aceite em: 17/03/2019

Publicado em: 06/05/2019 